\title{
The Role of Lipids During Embryonic Development of the Euphausiids Euphausia Pacifica and Thysanoessa Spinifera
}

Se-Jong Ju

H. Rodger Harvey

Old Dominion University, hharvey@odu.edu

Jaime Gómez-Gutiérrez

William T. Peterson

Follow this and additional works at: https://digitalcommons.odu.edu/oeas_fac_pubs

Part of the Developmental Biology Commons, Marine Biology Commons, and the Oceanography Commons

\section{Repository Citation}

Ju, Se-Jong; Harvey, H. Rodger; Gómez-Gutiérrez, Jaime; and Peterson, William T., "The Role of Lipids During Embryonic Development of the Euphausiids Euphausia Pacifica and Thysanoessa Spinifera" (2006). OEAS Faculty Publications. 148.

https://digitalcommons.odu.edu/oeas_fac_pubs/148

\section{Original Publication Citation}

Ju, S.J., Harvey, H.R., Gómez-Gutiérrez, J., \& Peterson, W.T. (2006). The role of lipids during embryonic development of the euphausiids euphausia pacifica and thysanoessa spinifera. Limnology and Oceanography, 51(5), 2398-2408. doi: 10.4319/

lo.2006.51.5.2398 


\title{
The role of lipids during embryonic development of the euphausiids Euphausia pacifica and Thysanoessa spinifera
}

\author{
Se-Jong $J u^{1}$ and H. Rodger Harvey
}

University of Maryland Center for Environmental Science, Chesapeake Biological Laboratory, Solomons, Maryland 20688

\section{Jaime Gómez-Gutiérrez}

Centro Interdisciplinario de Ciencias Marinas, Departamento de Plancton y Ecología Marina, 23096, La Paz, Baja California Sur, México

\section{William T. Peterson}

National Marine Fisheries Service, Hatfield Marine Science Center, Newport, Oregon 97365

\begin{abstract}
To understand the role of lipids during early embryogenesis, major lipid classes together with individual fattyacid and sterol composition were determined in embryos from multiple developmental stages of the euphausiids Euphausia pacifica and Thysanoessa spinifera. Average lipid content in embryos of E. pacifica and T. spinifera from the earliest stage (multicell) were 4.45 and $3.69 \mu \mathrm{g} \mathrm{embryo}^{-1}$, respectively. During development, the lipid content decreased at similar rates in the embryos of both species. In contrast to many crustacean eggs, phospholipids were the dominant lipid class in all embryonic stages, with decreasing concentrations seen during development. Individual fatty acids and sterols showed selective utilization during early developmental stages. The dominant fatty acids were $16: 0$ and $16: 1 \omega 7$ and 20:5 $\omega 3$, with most polyunsaturated fatty acids preferentially metabolized throughout early stages. An exception was 22:6 13 , which remained near constant through all stages. Cholesterol was the dominant sterol ( $>82 \%$ of total sterols) in embryos, with only minor changes during development. The appearance of algal sterols and fatty alcohols, including phytol, in $T$. spinifera embryos suggests that considerable amounts of algal lipids are directly allocated to eggs during vitellogenesis. Despite the substantial changes in lipid amount and composition during embryo development, the presence of phospholipids as the dominate lipid store acts to moderate changes in egg-sinking rate for both species until the late (early and late limb-bud) stages of development.
\end{abstract}

Along the Oregon coast, two temperate euphausiid species, Euphausia pacifica Hansen and Thysanoessa spinifera Holmes, account for about $90 \%$ of euphausiid abundance and biomass (Gómez-Gutiérrez et al. 2005) and play significant roles in the marine ecosystem as links between primary producers and top predators, such as fishes, marine birds, and mammals. To understand the ecologic niche that these species occupy, we must study their life cycles and vital rates (i.e., fecundity, growth, and

${ }^{1}$ Corresponding author (sejongju@gmail.com).

\section{Acknowledgments}

We thank Leah Feinberg, Tracy Shaw, Julie Keister, Jesse Lamb, Anders Røestad, and Mitch Vance for their assistance in the collection of live euphausiids.

This research was partially supported by a Mamie Markham Research Award from Oregon State University, Hatfield Marine Science Center (HMSC), and the NEP-GLOBEC program to H.R.H. (OCE-0000732) and W.T.P. (NA67RJ0151). J.G.G. was also supported by an SNI-II fellowship, by COFAA-IPN, EDIIPN, and a doctoral CONACyT grant (122676) to study at Oregon State University. Contribution 3967 of The University of Maryland Center for Environmental Science and contribution 288 for U.S. GLOBEC program. Ship time and staff assistance in 1999-2000 were provided by the Office of Naval Research (National Ocean Partnership Program) and ship time in 2000 2002 by the U.S. GLOBEC program. mortality). Yet, their reproductive strategies and recruitment mechanisms remain poorly understood. Euphausiid embryos (rather than "eggs," which refers strictly to unfertilized oöcytes) are delicate and difficult to manipulate experimentally, and as a consequence, relatively few studies have examined the embryology, hatching mechanism, and vertical distribution (Marschall and Hirche 1984; Iguchi and Ikeda 1994; Gómez-Gutiérrez 2003). The embryos of most broadcast euphausiid species, including $E$. pacifica and $T$. spinifera, have a unique feature during their early embryonic development: they are released near surface waters and sink rapidly to depth, where they may hatch. After hatching, the nonfeeding larval stages (nauplii and metanauplii) ascend and arrive in the surface water at metamorphosis to the first feeding stage, calyptopis 1 (Quetin and Ross 1984; Gómez-Gutiérrez 2003). The daily migration of adults and sinking of eggs (i.e., embryos) separate the parental stock from their eggs (Brinton and Willie 1976), which makes estimations of recruitment rate (or mortality) of the embryos difficult.

Embryogenesis of $E$. pacifica from fertilization to hatching of the first nauplius has been postulated to occur during transit of embryos to deep waters, with increased sinking rates in older stages (Ross 1981; Quetin and Ross 1984; Gómez-Gutiérrez 2003). Previous studies have 
demonstrated that sinking rates of euphausiid embryos vary during development, with gradual decline as embryos develop through the multicell cleavage to gastrula stage (Quetin and Ross 1984; Ross and Quetin 1985; George and Strömberg 1985). Differences in the sinking rates of embryos may result from (1) external abiotic factors, such as local seawater density and current speed and direction, (2) changes in embryo biochemical composition associated with development, or (3) both external abiotic factors and changes in embryo biochemical composition (Amsler and George 1985; George and Strömberg 1985; Hofmann and Hüsrevoğlu 2003). Among the major biochemical components of developing embryos, lipids are considered one of the most important sources of metabolic energy. In marine crustaceans, the major lipid components include wax esters and triacylglycerols used for energy storage and phospholipids and sterols used as major structural (i.e., membrane) lipids. Each lipid component has a different density (Hadley 1985), and, thus, lipid content and composition can influence buoyancy of eggs, embryos, and animals (Kattner and Hagen 1998; Visser and Jónasdóttir 1999; Campbell and Dower 2003). Triacylglycerols are the most common form of energy storage in eggs, as well as for later life stages, of most marine organisms (Cowey et al. 1985; Harrison 1990; Sargent 1995). However, exceptions exists; the Antarctic euphausiid E. crystallorophias spawns embryos that are both high in lipids (i.e., $51 \%$ of dry weight) and composed of large amounts of low-density wax esters, which leads to embryos that are neutrally buoyant (Harrington and Thomas 1987; Kattner and Hagen 1998). This adaptation may provide some advantage by maintaining developing embryos in surface waters of its shelf habitat. Some copepods, such as Calanus finmarchicus, however, contain wax esters that have a greater compressibility and larger thermal expansion than seawater, which allows animals with large wax-ester stores to become more negatively buoyant as they sink to deeper waters during winter diapause (Visser and Jónasdóttir 1999; Campbell and Dower 2003). Similar changes in sinking rates would be expected for euphausiid eggs and embryos if they were rich in wax esters and other biochemical components (e.g., protein) that might also affect density (e.g., Irigoien 2004; Visser and Jónasdóttir 1999). Albessard et al. (2001) and Mayzaud et al. (2003) observed phospholipids as an important lipid component in some euphausiids and have suggested that they might be used as major energy sources for reproduction and embryonic development. Lipids apparently represent not only a major source of energy for developing euphausiids but also one of several biochemical components that could affect the depth of embryos at hatch.

The objective of this study was to examine the role of lipids in E. pacifica and T. spinifera embryos by following lipid classes, together with detailed information on fatty acids and sterols, during embryonic development stages. Quantifying such changes in embryo-lipid composition during development also allows estimation of overall embryo density and, thus, the impact of biochemical compositional changes on sinking rates in the field.

\section{Materials and methods}

Embryo collection-Mature females were collected at night by use of a $60-\mathrm{cm}$ diameter Bongo net with a $333-\mu \mathrm{m}$ mesh during nine oceanographic cruises along the Newport Hydrographic line ( $\mathrm{NH}$ line, $\left.44^{\circ} 38^{\prime} \mathrm{N}\right)$ in the Oregon upwelling system as part of the U.S. GLOBEC sampling program. The zooplankton catch was diluted into 20-liter insulated containers filled with surface seawater. Females were transported to a constant-temperature cold room $\left(10^{\circ} \mathrm{C}\right)$ at Hatfield Marine Science Center (HMSC) within 2 to $3 \mathrm{~h}$ after collection. Healthy appearing, gravid females (maturity stage IV, purple-colored gonad) were sorted and placed into 2-liter bottles filled with sieved (64- $\mu \mathrm{m}$ mesh) surface seawater from the stations where the females were collected. One female was placed in each bottle. Variable numbers of replicates were made for each cruise, according to the availability of gravid females in samples. Bottles were incubated under constant temperature of $10^{\circ} \mathrm{C} \pm 0.5^{\circ} \mathrm{C}$, with a light cycle of $12 \mathrm{~h}$ darkness and $12 \mathrm{~h}$ low light. The females were monitored every hour after incubation to observe spawning and to estimate the age of the brood. If a female spawned, the embryos were collected with a $64-\mu \mathrm{m}$ mesh sieve. Embryos were counted, and the chorion (the outmost membrane of the embryo) and embryo diameter measured at different developmental stages. Individual eggs of the same developmental stage were sorted into different petri dishes. Egg development was also monitored by use of a digital camera (Olympus Camedia 3040 Zoom, $3.1 \times$ $10^{-6}$ pixels resolution) mounted on a stereomicroscope. Digital pictures were recorded every $10 \mathrm{~min}$ during the first 8 to $10 \mathrm{~h}$ of embryo development, every hour between 10 to $15 \mathrm{~h}$, and every 2 to $4 \mathrm{~h}$ after $15 \mathrm{~h}$ until the end of the experiment. The eggs of $T$. spinifera are very sticky, and incubations with this species relied on Teflon bottles or polycarbonate jars and a dissecting stereomicroscope to directly observe embryos without handling.

The early embryonic developmental stages were classified into seven major stages, according to the developmental sequence previously described (George and Strömberg 1985; Quetin and Ross 1984, 1989; Gómez-Gutiérrez 2002). Stages were defined as follows:

- Single cell (SC). A recently spawned embryo, perivitelline space minute, and no sign of cleavage.

- Multiple cell (MC). The initial stage of cleavage to multicellular.

- Blastula (BL). The formation of one layer of cells.

- Gastrula (GL). The formation of two layers of cells enclosing a central cavity (archenteron).

- Early limb-bud (eLB). The embryo is transformed into nauplius, the naupliar appendages still connected with the body by a membrane, and limb primordia visible in lateral view as ridges.

- Late limb-bud (ILB). The distal ends of the limbs have become free, tubelike structures.

- Twitch (TW). The nauplius has taken shape, no membrane surrounds it, appendages are freely sus- 
pended from the body, and, in a live embryo, the nauplius moves the appendages and has a pulsating heart.

The development time of each embryo stage at $10^{\circ} \mathrm{C}$ for both species was estimated and reported by GómezGutiérrez (2002, 2003). For each euphausiid species, embryos (27 to 90) were collected for each of three developmental stages (MC, GL, and ILB for E. pacifica and $\mathrm{MC}, \mathrm{BL}$, and $\mathrm{eLB}$ for $T$. spinifera) from the same brood stock and immediately frozen in liquid nitrogen and stored at $-80^{\circ} \mathrm{C}$. For lipid analysis, embryos from the same developmental stage were pooled, which provided a total of six composite samples composed of multiple embryos at the same developmental stage.

Lipid extraction and analysis-Total lipids were extracted from freshly thawed embryos with a mixture of $\mathrm{CH}_{2} \mathrm{CL}_{2}: \mathrm{MeOH}(1: 1)$ in solvent-washed, 25-mL, screwcap glass/Teflon-lined cap test tubes with probe sonication, as previously described (Harvey et al. 1987). The solvent was removed by rotary evaporation, and then total lipid redissolved in 50-100 $\mu \mathrm{L}$ of $\mathrm{CH}_{2} \mathrm{CL}_{2}: \mathrm{MeOH}$ (2:1). Subsamples of lipid extracts were used for lipid-class analysis, and the remaining fraction was used for individual lipid (i.e., fatty acids and sterols) analysis.

Major lipid-class composition was determined by thinlayer chromatography with flame ionization detection (TLC-FID) that utilized an Iatroscan MK-V Analyzer (e.g., Ju and Harvey 2004). Aliquots $(1-2 \mu \mathrm{L})$ of total extracts were spotted onto replicate S-III Chromarods, focused in $\mathrm{CH}_{2} \mathrm{CL}_{2}: \mathrm{MeOH}(1: 1)$ and developed in hexane: diethyl ether:formic acid $(85: 15: 0.2)$ for separation of major lipid classes. This solvent system allowed individual neutral lipid classes to be separated and identified; phospholipids remained at the origin and were not quantified individually. Lipid classes were identified and calibrated by use of a mixture of commercial lipid standards (Sigma). Peak areas were integrated (HP ChemStation) and quantified by use of a standard lipid mix of similar composition run in parallel. Total-lipid content was determined by the summation of all lipid classes quantified by TLC-FID. Overall precision for total lipid and major classes was never greater than $\pm 10 \%$.

Quantification of individual components in neutral (alcohols and sterols) and polar (fatty acids) lipid fractions were performed as previously described (Ederington et al. 1995). Internal standards ( $5 \alpha$-cholestane for neutral and nonadecanoic acid for polar) were added to the remaining fraction of the total-lipid extract. Solvent was dried under $\mathrm{N}_{2}$ and the sample subjected to alkaline hydrolysis by use of $0.5 \mathrm{~mol} \mathrm{~L}^{-1}$ methanolic $\mathrm{KOH}$, with gentle heating. After cooling and addition of water, neutral lipid fractions were partitioned three times with a mixture of hexane: diethyl ether $(9: 1)$. The neutral fraction was treated with $30 \mu \mathrm{L}$ of bis(trimethylsilyl) trifluoroacetamide (BSTFA) with 25\% pyridine to convert free alcohols to their corresponding trimethylsilyl (TMS) esters. Polar lipid fractions that contained fatty acids were partitioned similarly after acidification to $\mathrm{pH} 2$ and converted to fatty-acid methyl esters (FAMES) by use of $\mathrm{BF}_{3}-\mathrm{MeOH}$. A subsample of FAMES was treated with dimethyl disulfide (DMDS) to determine double-bond position of monounsaturated fatty acids (Nichols et al. 1986). Procedural blanks were processed in parallel with samples that had similar internal standards. Polar and neutral lipids were quantified by capillary-gas chromatography (HP-5890-II GC) equipped with a flame ionization detector. Separations were performed with DB-5MS fused-silica column (60-m length $\times 0.32-\mathrm{mm}$ i.d. $\times 0.25-\mathrm{m}$ film thickness) and hydrogen as carrier gas. Samples were injected in splitless mode at an initial oven temperature of $50^{\circ} \mathrm{C}$ and an injector temperature of $225^{\circ} \mathrm{C}$. The oven temperature was then ramped at $15^{\circ} \mathrm{C} \mathrm{min}-1$ to $120^{\circ} \mathrm{C}$ and thereafter $4^{\circ} \mathrm{C} \mathrm{min}-1$ to $300^{\circ} \mathrm{C}$ and held at $300^{\circ} \mathrm{C}$ for 10 and 20 min for polar and neutral lipids, respectively. All data were processed by use of a dedicated data system (HP ChemStation), with quantification based on peak-area response compared with the internal standards. Structural identification utilized gas chromatography-mass spectrometry (GC-MS; Agilent 6870 GC with Agilent 5973 MSD) operating at $70 \mathrm{eV}$, with mass range acquisition of 50-700 atomic mass units. The column and temperature programs for the GC-MS are similar to that described above, with helium used as a carrier gas and injector temperature of $250^{\circ} \mathrm{C}$.

Implications of biochemical-compositional change on embryo-sinking rates-To evaluate how the sinking rates of embryos are affected by changes in biochemical composition during embryonic development, we estimated egg densities under three different hypothetical scenarios (see Web Appendix 1 for assumptions and calculations, http://www.aslo.org/lo/toc/vol_51/issue_5/2398al.pdf ). In the first scenario, only the amount of lipid present during embryonic development could affect embryo density, with no changes to other biochemical components. In this scenario, we also assumed that the lipid composition remained constant throughout (despite known differences) to test how lipid content alone might affect embryo-sinking rates. In the second case, the lipid density in the first scenario was adjusted to the compositional-specific density of lipids on the basis of actual lipid measurements (given in Table 1). In the third scenario, changes in all major biochemical components of embryos were included to estimate density during embryonic development. For the third scenario, protein dynamics during development are unknown for these species, and, thus, the change of protein content through embryogenesis was assumed to be equal to that for E. superba estimated by Amsler and George (1985). For all three scenarios, we assumed SC embryos were spawned shallower than 50-m deep, in keeping with the observation that most spawning occurs during the night near the surface (Gómez-Gutiérrez 2003). The potential for osmotic regulation of embryos and, thus, small density changes, was not considered (e.g., McAllen et al. 1998), and the density of water was assumed equal to that of the surrounding seawater at any given depth. 
Table 1. Total-lipid content ( $\mu \mathrm{g}$ embryo $^{-1}$ ) and lipid-class composition (\% of total lipids) during three major embryonic development stages of E. pacifica (MC, GL, and ILB stages) and T. spinifera (MC, BC, and eLB stages).

\begin{tabular}{|c|c|c|c|c|c|c|c|c|}
\hline \multirow[b]{2}{*}{ Species } & \multirow[b]{2}{*}{ Embryo stage } & \multicolumn{5}{|c|}{ Lipid class (\% of total) } & \multirow{2}{*}{$\begin{array}{l}\text { Density of lipid* } \\
\qquad\left(\mathrm{g} \mathrm{cm}^{-3}\right)\end{array}$} & \multirow{2}{*}{$\begin{array}{l}\text { Total lipids } \\
\left(\mu \mathrm{g}_{\text {embryo }}^{-1}\right)\end{array}$} \\
\hline & & PL & ST & FFA & TAG & WE & & \\
\hline \multirow[t]{3}{*}{ E. pacifica } & $\mathrm{MC}$ & 57.8 & 4.0 & 7.0 & 29.5 & 1.7 & 0.986 & $4.45(50) \dagger$ \\
\hline & GL & 86.8 & 1.1 & 0.2 & 11.0 & 0.9 & 1.036 & $3.18(60)$ \\
\hline & 1LB & 64.5 & 5.0 & 0.8 & 25.9 & 3.8 & 1.017 & $1.24(29)$ \\
\hline \multirow[t]{3}{*}{ T. spinifera } & $\mathrm{MC}$ & 58.2 & 3.8 & 5.9 & 26.0 & 6.1 & 0.996 & $3.69(66)$ \\
\hline & $\mathrm{BL}$ & 49.1 & 3.8 & 4.9 & 28.9 & 13.3 & 0.980 & $3.75(92)$ \\
\hline & eLB & 66.7 & 4.0 & 0.8 & 24.1 & 4.4 & 1.010 & $1.60 \pm 0.04(25$ and 27$)$ \\
\hline
\end{tabular}

* Density of each lipid class was obtained from Hadley (1985), with exception of phospholipids, whose density was estimated by Grain's method (Nelken $1990)$; Phospholipids $(\mathrm{PL})=1.05$, sterols $(\mathrm{ST})=1.07$, free fatty acids $(\mathrm{FFA})=0.87$, triacyglycerols $(\mathrm{TAG})=0.92$, and wax esters $(\mathrm{WE})=0.82 \mathrm{~g} \mathrm{~cm}^{-3}$. $\uparrow$ Number of embryos pooled for analysis.

$\$$ Two separate pooled samples were analyzed.

\section{Results}

Lipid content and class composition-Total-lipid content of the MC embryos of E. pacifica and T. spinifera in composite samples were 4.45 and $3.69 \mu \mathrm{g}$ embryo $^{-1}$, respectively. During embryonic development, lipid content of both species steadily decreased at relatively similar rates ( $0.11 \mu \mathrm{g} \mathrm{embryo}^{-1} \mathrm{~h}^{-1}$ [Table 1]). The embryos of $E$. pacifica contained slightly higher lipid than those of $T$. spinifera, particularly at MC stage (Table 1). Unexpected was the observation that phospholipids (PL) constituted the major lipid class of early developmental stages in both euphausiid species (49-87\% of total lipids). A substantial decrease in concentration of PL was seen during later stages of embryonic development and was more pronounced for E. pacifica (Table 1). The second most-abundant lipid class was triacyglycerol (TAG) (11-30\% of total lipids) followed by wax esters (WE), sterols (ST), and free fatty acids (FFA) ( $<13 \%$ of total lipids). Relatively higher amounts of WE were present in the embryos of $T$. spinifera, whereas only trace amounts of WE were detected in the embryos of $E$. pacifica. A substantial decrease in concentration of PL was seen during later stages of embryonic development and was more pronounced for E. pacifica (Table 1). The observed changes in lipid-class composition during embryogenesis also have implications for embryo density and, thus, sinking rates through the water column, especially for $T$. spinifera, which contained relatively higher wax-ester content.

Fatty-acid and sterol composition-During embryogenesis, total fatty acids showed a similar trend as total-lipid content; they decreased at similar rates $(0.11$ and $0.13 \mu \mathrm{g}$ embryo $^{-1} \mathrm{~h}^{-1}$ for E. pacifica and T. spinifera, respectively) (Table 2). The fatty-acid distributions of embryos were also similar between the two species, with the addition of significant amounts of the branched $\mathrm{C} 18$ (anteiso 18:0) seen in the embryos of E. pacifica (Table 2). Among fatty acids, 16:0, 16:1 $\omega 7$, and 20:5 $\omega 3$ (eicosapentaenoic acid [EPA]) were dominant, with considerable changes observed during early embryonic development for both euphausiid species. The concentration (per embryo) of these major fatty acids decreased during embryonic development, even though the relative abundance of the 16:0 acid increased. On the basis of grouped fatty-acid composition, polyunsaturated fatty acids were preferentially metabolized throughout embryogenesis, particularly for E. pacifica (Fig. 1). Yet, the concentration of 22:6 $\omega 3$, known as an essential fatty acid for embryonic and larval development (e.g., Watanabe 1993), showed little change through the stages examined.

Total sterols in embryos of $T$. spinifera steadily decreased (5.6 pg embryo ${ }^{-1} \mathrm{~h}^{-1}$ ) through early development, but for E. pacifica embryos, sterols were principally used during early stages between MC and GL (Table 3). Sterol distributions of E. pacifica embryos were much simpler than those of T. spinifera. Even though cholesterol was the primary structure ( $>82 \%$ of total sterols) in the embryos for both species, minor amounts of other sterols were also detected. Notable amounts of various algal sterols and trace amounts of fatty alcohols and phytol were present in embryos of $T$. spinifera during earlier stages (MC and $\mathrm{BL}$ ).

Compositional changes and embryo-sinking rates-The calculated densities of fresh embryos were 1.0503 and $1.0535 \mathrm{~g} \mathrm{~cm}^{-3}$ for E. pacifica and T. spinifera, respectively. These calculated embryo densities are near the value reported for E. superba embryos (1.0459 $\mathrm{g} \mathrm{cm}^{-3}$ ) (Quetin and Ross 1984) but less than embryos of the copepods Calanus glacialis (1.0556) and C. finmarchicus (1.0639 and $1.0812 \mathrm{~g} \mathrm{~cm}^{-3}$ ) (Knutsen et al. 2001). From this calculation (Web Appendix 1, Eq. A2), the average wet weights of fresh embryos of E. pacifica and T. spinifera are 32.6 and $27.9 \mu \mathrm{g}$ embryo $^{-1}$, respectively. Quetin and Ross (1984) and Amsler and George (1985) have previously shown for $E$. superba that calculated embryo weights that utilize density are not significantly different from the directly measured weights. By application of this calculated embryo wet weight, density estimates were made at different embryo stages. If the embryo density and its lipid content are known, then the fraction of other major biochemical components (mainly protein and seawater) in the embryos can also be estimated (see Web Appendix 1, Eq. A3). By use of these initial values, the embryo densities of different embryonic stages in all three different scenarios were calculated and shown in Table 4 and Fig. 2. 
Table 2. Fatty-acid composition (\% of total fatty acids) in embryos of E. pacifica and T. spinifera during development.

\begin{tabular}{|c|c|c|c|c|c|c|}
\hline \multirow[b]{2}{*}{ Fatty acid } & \multicolumn{3}{|c|}{ E. pacifica } & \multicolumn{3}{|c|}{ T. spinifera } \\
\hline & $\operatorname{MC~}(50)^{*}$ & GL (60) & ILB (29) & MC (66) & BL (92) & eLB (27) \\
\hline \multicolumn{7}{|l|}{ Saturates } \\
\hline $14: 0$ & 5.5 & 1.7 & 4.2 & 4.8 & 5.6 & 3.3 \\
\hline $15: 0$ & 0.9 & 0.3 & 0.6 & 0.4 & 0.4 & 0.5 \\
\hline $16: 0$ & 21.3 & 30.4 & 34.1 & 28.7 & 0.8 & 32.0 \\
\hline $17: 0$ & 0.7 & 0.3 & 0.3 & 0.3 & 0.2 & 0.3 \\
\hline $18: 0$ & 7.1 & 3.9 & 2.9 & 3.2 & 2.7 & 3.1 \\
\hline $20: 0$ & $\operatorname{Tr}$ & 0.1 & 0.1 & $\operatorname{Tr}$ & $\operatorname{Tr}$ & 0.2 \\
\hline $22: 0$ & $\operatorname{Tr}$ & $\operatorname{Tr}$ & $\operatorname{Tr}$ & 0.2 & $\operatorname{Tr}$ & 0.3 \\
\hline \multicolumn{7}{|l|}{ Monounsaturates } \\
\hline $16: 1 \omega 9$ & 0.2 & 0.2 & 0.2 & 0.2 & 0.2 & 0.2 \\
\hline $16: 1 \omega 7$ & 10.8 & 8.1 & 7.1 & 11.2 & 12.7 & 9.4 \\
\hline $16: 1 \omega 5$ & 0.2 & 0.3 & 0.4 & 0.2 & 0.3 & 0.2 \\
\hline $16: 1 \omega 3$ & 0.2 & 0.1 & 0.1 & 0.2 & 0.2 & 0.1 \\
\hline $18: 1 \omega 9$ & 6.8 & 8.0 & 5.5 & 7.7 & 9.0 & 9.4 \\
\hline $18: 1 \omega 7$ & 8.3 & 8.1 & 5.6 & 7.3 & 7.8 & 5.1 \\
\hline $18: 1 \omega 5$ & 0.1 & 0.3 & 0.3 & 0.1 & 0.1 & 0.2 \\
\hline $20: 1^{+}$ & 0.7 & 1.3 & 1.3 & 1.3 & 0.8 & 2.5 \\
\hline $22: 1^{+}$ & 1.0 & 0.1 & 0.1 & 0.7 & 0.4 & $\operatorname{Tr}$ \\
\hline \multicolumn{7}{|l|}{ Polyunsaturates } \\
\hline $16: 4 \omega 1$ & 1.0 & 0.5 & $\operatorname{Tr}$ & 0.8 & 1.1 & 0.4 \\
\hline $16: 3 \omega 4$ & 1.1 & 0.6 & 0.8 & 0.9 & 1.0 & 0.2 \\
\hline $16: 2 \omega 6$ & 1.9 & 2.7 & 2.5 & 1.6 & 1.7 & 1.4 \\
\hline $18: 4 \omega 3$ & 1.5 & 1.1 & 0.7 & 9.1 & 1.0 & 0.7 \\
\hline $18: 3 \omega 3$ & 0.2 & 0.1 & $\operatorname{Tr}$ & 0.1 & 0.1 & 0.1 \\
\hline $18: 2^{+}$ & 1.1 & 1.4 & 1.4 & 1.1 & 1.0 & 0.6 \\
\hline $20: 5 \omega 3$ & 25.8 & 19.0 & 13.4 & 16.0 & 19.2 & 14.3 \\
\hline $20: 4 \omega 6$ & 0.7 & 0.2 & $\operatorname{Tr}$ & 0.3 & 0.4 & 0.2 \\
\hline $20: 4 \omega 3$ & 0.3 & $\operatorname{Tr}$ & - & 1.2 & 0.3 & 0.2 \\
\hline $20: 2 \omega 6$ & 0.2 & $\operatorname{Tr}$ & - & - & 0.1 & 0.3 \\
\hline $22: 6 \omega 3$ & 2.4 & 4.8 & 7.5 & 1.3 & 2.0 & 11.8 \\
\hline $22: 5 \omega 6$ & $\operatorname{Tr}$ & 0.3 & 0.2 & $\operatorname{Tr}$ & $\operatorname{Tr}$ & 0.5 \\
\hline $22: 5 \omega 3$ & 0.4 & - & - & 0.4 & 0.3 & 0.6 \\
\hline \multicolumn{7}{|l|}{ Branched } \\
\hline$i 15: 0$ & 0.1 & 1.1 & 3.8 & 0.1 & 0.1 & 0.3 \\
\hline$a 15: 0$ & $\operatorname{Tr}$ & 0.4 & 0.9 & 0.1 & $\operatorname{Tr}$ & 0.6 \\
\hline$a 16: 0$ & $\operatorname{Tr}$ & 0.3 & 0.4 & - & - & 0.1 \\
\hline$i 17: 0$ & 0.2 & 0.2 & 0.3 & 0.2 & 0.2 & 0.2 \\
\hline$a 17: 0$ & 0.1 & 0.3 & 0.6 & 0.1 & 0.1 & 0.6 \\
\hline$a 18: 0$ & 4.3 & 4.9 & 3.9 & 0.1 & 0.1 & 0.2 \\
\hline Total \% SAFA & 30.4 & 35.8 & 42.1 & 37.6 & 39.6 & 39.6 \\
\hline Total \% MUFA & 28.3 & 26.4 & 21.0 & 29.0 & 31.6 & 27.0 \\
\hline Total \% PUFA & 36.7 & 30.7 & 26.9 & 32.8 & 28.2 & 31.3 \\
\hline Total \% BrFA & 4.6 & 7.1 & 10.0 & 0.6 & 0.6 & 2.1 \\
\hline Total FA $\left(\mu\right.$ e embryo $\left.^{-1}\right)$ & 4.5 & 2.2 & 1.1 & 3.6 & 4.2 & 1.0 \\
\hline
\end{tabular}

* Number of embryos pooled in the sample.

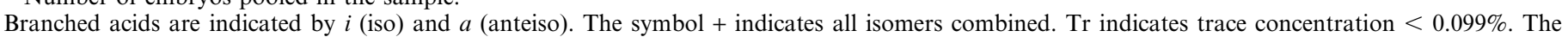
symbol - indicates concentration below detection limit or absent.

In general, embryo density was variable during development for the three scenarios tested. Trends of the embryo densities estimated from the first and second scenarios were similar, but significant differences were seen for developing embryos of E. pacifica, particularly at GL stage, when specific lipid classes (i.e., phospholipids) were preferentially utilized (Fig. 2). The addition of lipid-class information allows for a more constrained estimate of embryo density and, thus, a more realistic sinking-rate estimate as development proceeds. Both the first and the second scenarios showed the same trends, with increased embryo densities during embryonic development. Density in the third scenario was significantly lower, particularly during the later developmental stages, because protein was used for structural development at the early and late limbbud stages (Amsler and George 1985). The high density of protein $\left(1.2 \mathrm{~g} \mathrm{~cm}^{-3}\right.$ [Quetin and Ross 1984]) versus the low density of lipids $\left(0.99 \mathrm{~g} \mathrm{~cm}^{-3}\right.$ [measured here]) allows small changes in modeled-protein levels in the third scenario to have a significant impact on embryo density. By use of the calibrated embryonic density of each developmental stage of $E$. pacifica and $T$. spinifera, we can estimate sinking rates 

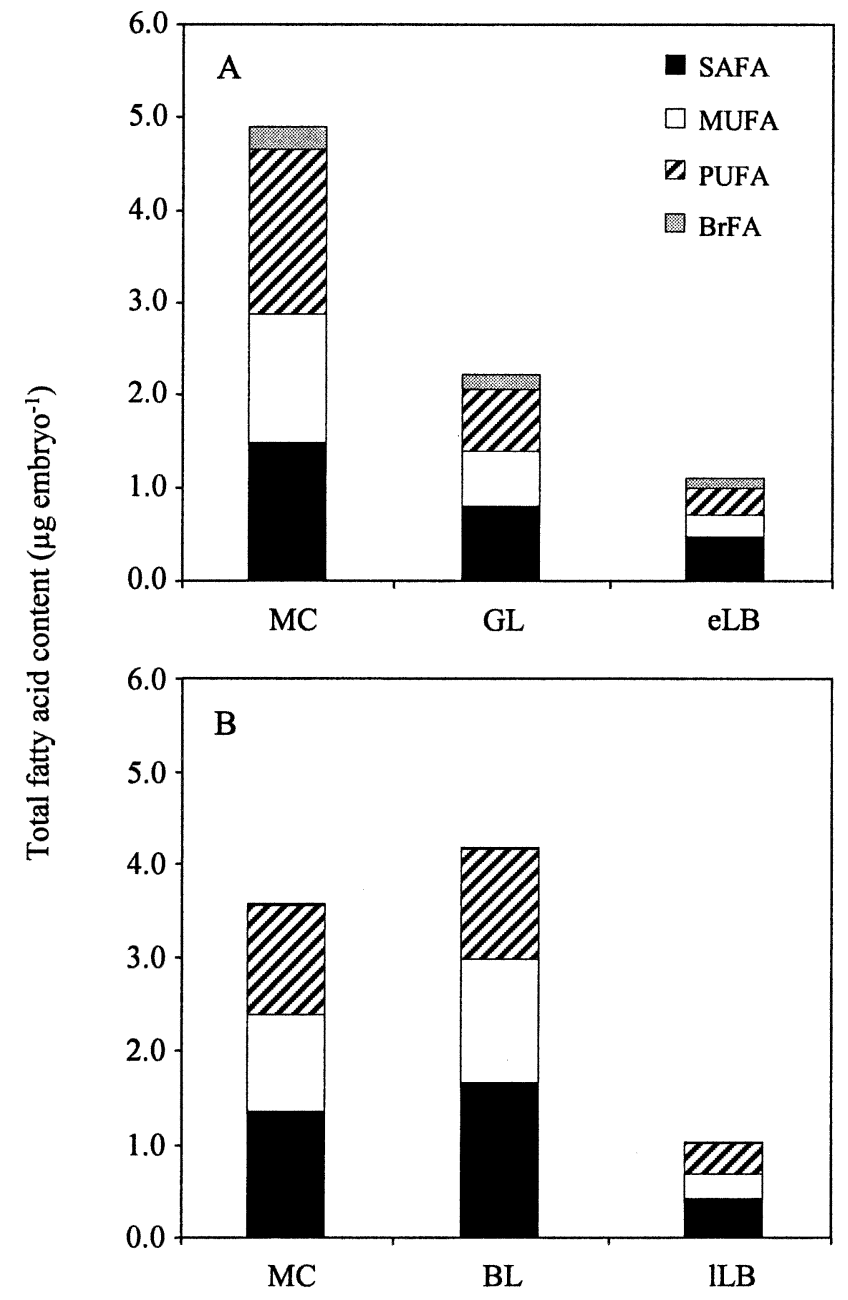

Embryonic developmental stages

Fig. 1. Total fatty-acid concentration ( $\mu \mathrm{g}$ embryo $\left.^{-1}\right)$ grouped by fatty-acid class in (A) Euphausia pacifica and (B) Thysanoessa spinifera embryos for three different developmental stages for each species: multiple-cell (MC), gastrula (GL), blastula (BL), early limb-bud (eLB), and late limb-bud (ILB). SAFA = saturated fatty acids, MUFA = monounsaturated fatty acids, PUFA = polyunsaturated fatty acids, and BrFA = branched fatty acids.

for both species as development proceeds (Web Appendix 1, Eq. A4). Calculated rates are shown in Table 4. These estimates suggest that the embryos of E. pacifica and $T$. spinifera are always negatively buoyant, with significant sinking rates (118-194 and $77-139 \mathrm{~m} \mathrm{~d}^{-1}$, respectively [Table 4]). Even though the embryos of $T$. spinifera showed similar densities as those of E. pacifica or slightly higher, their smaller size (i.e., diameter) leads to a lower predicted sinking rate for $T$. spinifera embryos. Among all three scenarios, sinking rates showed only minor differences during early developmental stages (from SC to BL). Sinking rates slow with later embryonic stages (ILB and eLB for both species), and the more detailed composition in the third scenario results in slower rates than those estimated under more simple scenarios. The slower sinking rates during the later stages may have resulted from the lower embryo density caused by protein utilization. By use of estimated sinking rates, together with measured development times at $10^{\circ} \mathrm{C}$ (Gómez-Gutiérrez 2003), the depth reached for embryos at different developmental stages was determined and is illustrated in Fig. 2. The overall trend indicates that the embryos of $T$. spinifera are found relatively shallower than those of E. pacifica at the equivalent developmental stage.

\section{Discussion}

Gómez-Gutiérrez (2003) reported that the average carbon content of E. pacifica decreased in each successive development stage, which suggests energy consumption by the embryo during development. Our study shows a steady decrease of lipids during embryogenesis, a result also shown during successive embryonic development stages of E. superba (Amsler and George 1985). Energetically, lipids yield $9.45 \mathrm{cal} \mathrm{mg}^{-1}$ (Brett and Groves 1979), which suggests that it contributed $0.0302 \mathrm{cal}^{\text {embryo }^{-1}}$ during early development of these two species. This estimate closely matches the estimation $\left(0.0331 \mathrm{cal} \mathrm{embryo}^{-1}\right)$ for the Antarctic species E. superba (Amsler and George 1985). Nevertheless, the energetic contribution of other biochemical components, including proteins and perhaps carbohydrates, cannot be ignored during embryo development. For example, increased protein utilization takes place for structural development at the two limb-bud stages and form naupliar limbs that will become the first and second antennae and the mandible (Amsler and George 1985). At MC stage, the embryos of E. pacifica had slightly higher lipid content than those of T. spinifera (Table 1). This difference may be associated with the characteristic egg size for each species. Gómez-Gutiérrez (2003) showed that mean chorion and embryo diameters, excluding the perivitelline space of E. pacifica (407 and $378 \mu \mathrm{m}$, respectively), were significantly greater than those for $T$. spinifera (363 and $353 \mu \mathrm{m}$, respectively), which would allow greater lipid stores. In fact, after hatching, nauplii of $E$. pacifica are larger and more robust than nauplii of $T$. spinifera, with an ovoid and more slender body shape.

Although phospholipids (PL) are generally known for their structural function, they have also been suggested to play an important role as energy storage for overwintering and reproduction in some euphausiid species (Hagen et al. 1996; Albessard et al. 2001; Mayzaud et al. 2003). The high abundance and decrease of absolute concentration of PL during development demonstrate that this lipid class not only is a structural component in embryos of these two euphausiid species but also acts as important energy stores. Phospholipids also include a significant amount of longchain polyunsaturated fatty acids known as essential components of adult E. pacifica and T. spinifera (Ju and Harvey unpubl.). Relatively higher amounts of WE were present in the eggs of $T$. spinifera, whereas only trace amounts of WE were detected in the embryos of E. pacifica. The lipid-class distribution in embryos for these species were not expected and is similar to the composition observed in the adult animals (Ju and Harvey unpubl.), 
Table 3. Sterol composition (\% of total sterols) and alcohol content ( $\left.\mu \mathrm{g} \mathrm{embryo}^{-1}\right)$ in the embryos of E. pacifica and T. spinifera during embryonic development.

\begin{tabular}{|c|c|c|c|c|c|c|}
\hline \multirow[b]{2}{*}{ Compound } & \multicolumn{3}{|c|}{ E. pacifica } & \multicolumn{3}{|c|}{ T. spinifera } \\
\hline & $\mathrm{MC}(50)^{*}$ & GL (60) & 1LB (29) & MC (66) & BL (92) & eLB (27) \\
\hline \multicolumn{7}{|l|}{ Sterols } \\
\hline Cholest-5.22-dien-3 $\beta$-ol & 2.1 & 2.7 & 2.0 & 0.7 & 0.8 & $\operatorname{Tr}$ \\
\hline Cholest-5-en-3 $\beta$-ol (cholesterol) & 95.6 & 94.8 & 96.4 & 82.4 & 96.2 & 99.9 \\
\hline Cholesta-5.24-dien-3 $\beta$-ol & 2.4 & 2.6 & 1.6 & 12.8 & 0.6 & $\operatorname{Tr}$ \\
\hline 24-Methylcholesta-5.24(28)-dien-3 $\beta$-ol & - & - & - & 2.3 & 1.3 & - \\
\hline 24-Methylcholest-5-en-3 $\beta$-ol & - & - & - & 0.5 & 0.4 & - \\
\hline 24-Ethylcholesta-5-en-3 $\beta$-ol & - & - & - & 1.0 & 0.6 & - \\
\hline 24-Ethylcholesta-5.24(28)Z-dien-3 $\beta$-ol & - & - & - & 0.3 & 0.1 & - \\
\hline Total sterols $\left(\mu \mathrm{g}\right.$ embryo $\left.{ }^{-1}\right)$ & 0.10 & 0.02 & 0.01 & 0.11 & 0.14 & 0.01 \\
\hline Total alcohols $\uparrow\left(\mu\right.$ g embryo $\left.^{-1}\right)$ & - & - & - & 0.01 & 0.01 & - \\
\hline Phytol $\left(\mu \mathrm{g}\right.$ embryo $\left.{ }^{-1}\right)$ & 0.08 & - & - & 0.15 & 0.21 & - \\
\hline
\end{tabular}

* Number of embryos pooled in the sample.

$\dagger$ Only 16:0 and 18:0 alcohols were found.

$\mathrm{Tr}$ indicates $<0.1 \%$. The symbol - indicates not detected.

which suggests the lack of selective lipid mobilization during egg formation. Lipids such as TAG, FFA, and ST steadily decreased during early embryogenesis for $T$. spinifera, but for E. pacifica, their utilization peaked during stages between MC and GL stages. The selective utilization of lipid classes (especially wax esters in $T$. spinifera embryos) and biochemical components during embryogenesis could affect embryo density and sinking rates in the water column.

Among fatty acids, 16:0, 16:1 $\omega 7$, and 20:5 $\omega 3$ (eicosapentaenoic acid [EPA]) were dominant, with considerable changes during early embryonic development for both euphausiid species. These fatty acids were also found to be major components in juveniles and adults of E. pacifica and $T$. spinifera in the Oregon region (Ju and Harvey unpubl.), and their presence in eggs reflects their direct transfer from brooding females. The concentration of 22:6 $\omega 3$, known as an essential fatty acid for embryonic and larval development (e.g., Watanabe 1993), showed little change through the developmental stages examined. The selective retention of the 22:6 63 fatty acid suggests that it may be reserved for the final stages of embryonic development, nonfeeding metanauplii and nauplii larval stages, or both. Euphausiids, as do other crustaceans, have limited capacity for de novo sterol synthesis, and, thus, sterols and fatty alcohols, including phytol, can provide useful indices as dietary (trophic) markers (Virtue et al. 1993; Ederington et al. 1995; Ju and Harvey 2004). The appearance of a number of algal sterols and alcohols in T. spinifera embryos suggests significant transfer of algal-derived lipids from gravid female into the gonad during oögenesis.

In general, the embryos of the broadcast euphausiid are negatively buoyant. An exception is the neritic Antarctic species E. crystallorophias, whose embryos are adapted to remain at near-surface waters (Harrington and Thomas 1987). Our results indicate that the embryos of E. pacifica and $T$. spinifera are also negatively buoyant, with estimated sinking rates of freshly spawned embryos (SC stage) about
$128 \mathrm{~m} \mathrm{~d}^{-1}$ for E. pacifica and $126 \mathrm{~m} \mathrm{~d}^{-1}$ for T. spinifera under laboratory conditions (Gómez-Gutiérrez 2003). Such embryo-sinking rates are similar to those estimated for the Antarctic E. superba (George and Strömberg 1985) and for $T$. longipedata from the North Atlantic (Williams and Lindley 1982). Yet, they are slower by almost half that of $E$. superba, as measured by Marschall (1983) and Quetin and Ross (1984). E. pacifica and T. spinifera embryo sinking rates are almost twice as fast as that estimated for eggs (i.e., embryos) of two Arctic euphausiid species, T. inermis and T. raschii (Timofeev 1990). These sinking rates represent average behavior of the population; embryo size greatly varies within and between species, both spatially and temporally, which has an impact on sinking rates (GómezGutiérrez 2003). Other factors are also important, including the tendency of the eggs of $T$. spinifera to attach to particles and debris (Gómez-Gutiérrez 2003).

Hatching rates are also temperature dependent, and both Quetin and Ross (1984) and George and Strömberg (1985) have shown that warmer temperatures accelerate hatching times. By use of the temperature-dependent hatching time observed for E. pacifica at $1{ }^{\circ} \mathrm{C}$ and $>20^{\circ} \mathrm{C}$ by Iguchi and Ikeda (1994) and our own measurements $\left(7^{\circ} \mathrm{C}, 10^{\circ} \mathrm{C}\right.$, and $15^{\circ} \mathrm{C}$ ), we find that development time can be estimated by $\mathrm{HT}=7.94 \times \mathrm{e}^{-0.1244(\mathrm{~T})}(r=0.974, p<0.001)$, where HT is hatching time expressed in days, and $\mathrm{T}$ is laboratory temperature of embryonic development $\left({ }^{\circ} \mathrm{C}\right)$. The average summer vertical-temperature structure at the same location (NH-line: $44.6^{\circ} \mathrm{N}$ ) where females were collected during the 1998-2003 sampling period have surface temperatures of $10^{\circ} \mathrm{C}$ near the coast, which warm up to $17^{\circ} \mathrm{C}$ offshore (160 km offshore) (Huyer et al. 2005). The maximum vertical-temperature gradient is typically $10^{\circ} \mathrm{C}\left(17^{\circ} \mathrm{C}\right.$ at surface to $7^{\circ} \mathrm{C}$ at $150-\mathrm{m}$ depth). Under these field conditions, if average, measured, embryo-sinking rates of $127 \mathrm{~m} \mathrm{~d}^{-1}$ are used for both species (assumed constant), and temperature-dependent hatching time is as described above, the maximum depth of embryo at hatching could 


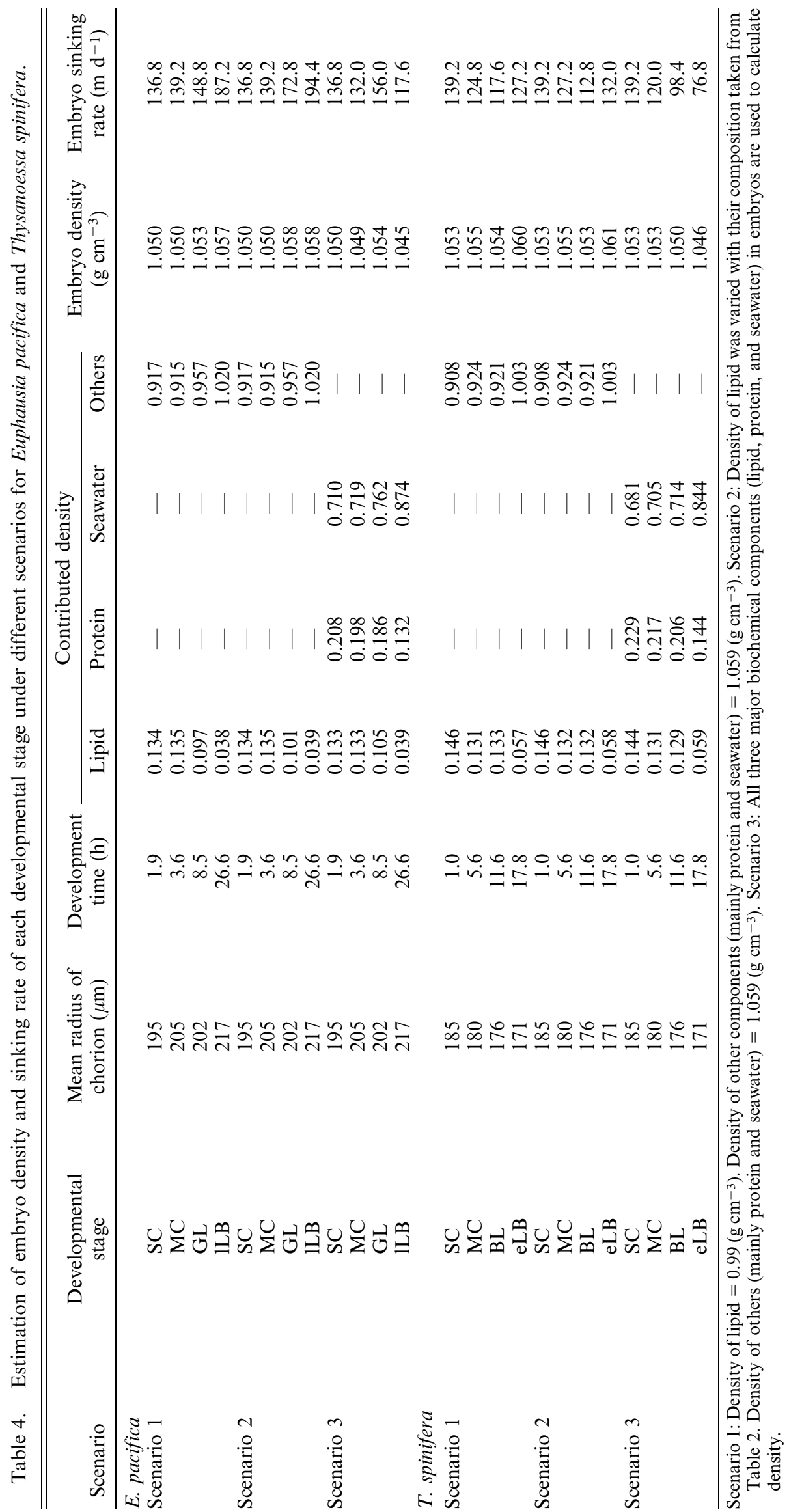




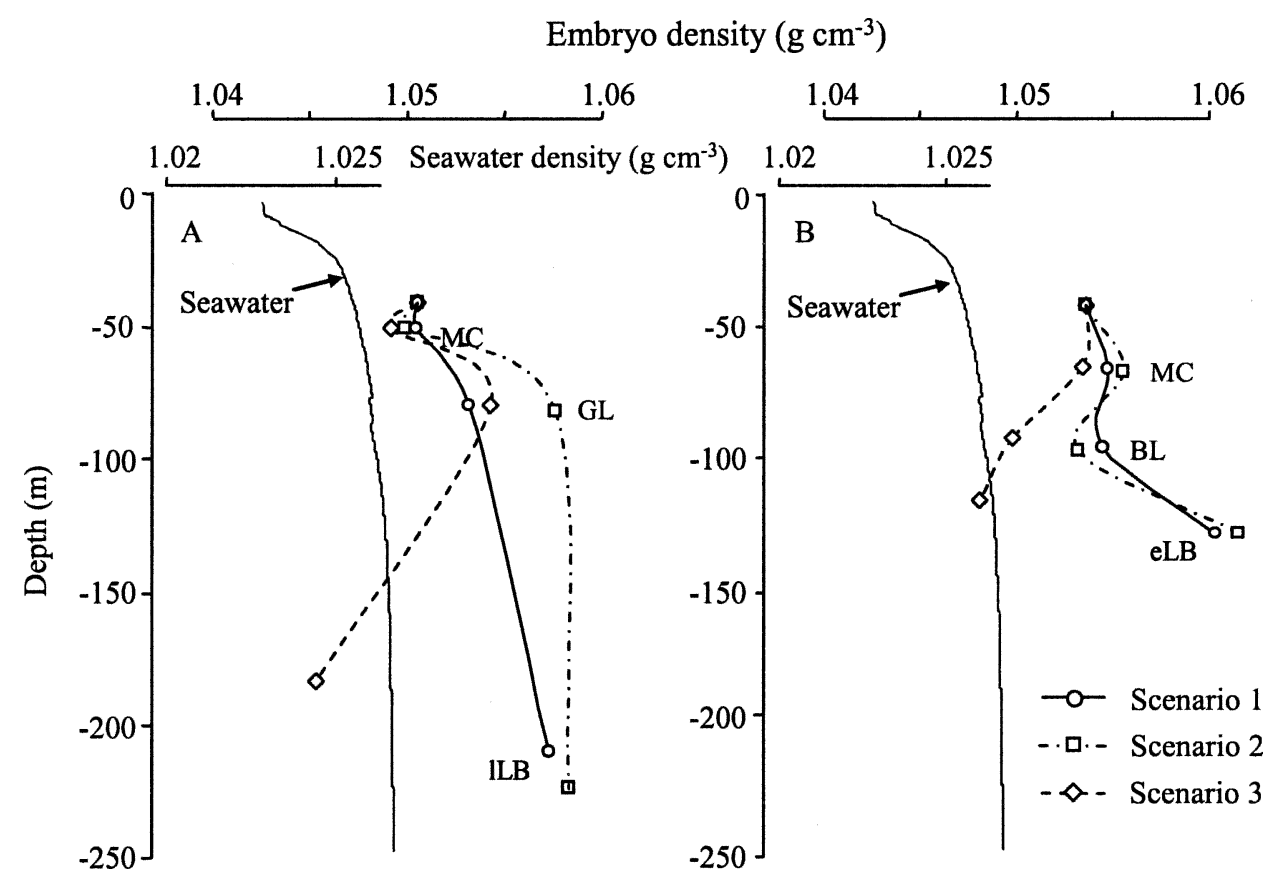

Fig. 2. Estimated embryo density of (A) Euphausia pacifica and (B) Thysanoessa spinifera through early embryogenesis compared with the mean seawater density off the Oregon coast. Development stages include multiple-cell (MC), gastrula (GL), blastula (BL), early limb-bud (eLB), and late limb-bud (ILB). Depth of each embryonic stage was determined by use of estimated sinking rate, with developmental time measured under laboratory condition (see Table 4).

range between $120 \mathrm{~m}$ and $421 \mathrm{~m}$ (at $17^{\circ} \mathrm{C}$ and $7^{\circ} \mathrm{C}$, respectively). At the average temperature of $10^{\circ} \mathrm{C}$, the hatch depth would be about $289 \mathrm{~m}$. This finding supports the hypothesis of Ross and Quetin (1985) that the hatchingtime dependence on temperature could have a significant effect on maximum hatching depth.

Lipids have been suggested not only to provide the energy requirement for embryo development but also to be important for the buoyancy (i.e., density) of the euphausiid embryos. Our results suggest that lipid content and composition in embryos shows substantial changes during development, which have the potential to alter their sinking rates. Although sinking rates of $T$. spinifera embryos might increase at depth as wax esters are compressed, embryos typically hatch within approximately $40 \mathrm{~h}$ of release at $10^{\circ} \mathrm{C}$. As a result, changes in sinking rate caused by compression of wax esters may not have an ecologically significant effect. For these two species, the presence of phospholipids provides the primary control over changes in buoyancy (and, thus, sinking rate) of embryos compared with species with triacylglycerol or wax-ester lipid stores.

Embryos of $E$. pacifica and $T$. spinifera appear to be similar to embryos of other broadcast euphausiids in their negative buoyancy. Detailed lipid composition shows that embryos and adults are similar in their overall lipid composition, which suggests that lipid is transferred directly from adults during egg formation, with little modification from dietary sources. As a consequence, we might expect lipid composition in embryos to vary with the nutritional condition of adult females and hatch success be strongly influenced by recent feeding success. More important is the unique presence of phospholipids as a major component of energy storage and utilization for developing embryos, which has not been observed in eggs (i.e., embryos) of other crustaceans. The higher density of phospholipids compared with other lipid fractions and similarity to seawater also serves to moderate changes in density during utilization. This factor is critical for euphausiid survival in continental-shelf waters, where eggs laid at the surface must hatch before reaching the underlying sediment to minimize the risk of benthic predation. The storage and utilization of PL, compared with more common lipids present a distinct advantage for embryo survival. The higher density of embryos initially allows them to sink rapidly from surface waters, which may help them to survive the predation by pelagic predators such as large medusae (Suchmann et al., in press), other zooplankton, and fish larvae. The metabolism of PL during embryonic development has a small affect on sinking rate compared with less-dense lipid classes (i.e., TAG, WE), which allows embryos to sink slowly and, thus, to hatch in deeper waters, but before being entrained in sediments. Although this mechanism has not been observed elsewhere, it provides a novel metabolic adaptation to enhance embryo survival. 


\section{References}

Albessard, E., P. Mayzaud, and J. Cuzin-Roudy. 2001. Variation of lipid classes among organs of the northern krill Meganyctiphanes norvegica, with respect to reproduction. Comp. Biochem. Physiol. A 129: 373-390.

Amsler, M. O., And R. Y. George. 1985. Changes in the biochemical composition of Euphausia superba Dana embryos during early development. Polar Biol. 4: 125-133.

Brett, J. R., AND T. D. D. Groves. 1979. Physiological energetics, p. 280-253. In W. S. Hoar, D. J. Randall and J. R. Brett [eds.], Fish physiology. Vol. 8. Academic.

Brinton, E., AND J. G. Willie. 1976. Distributional atlas of the euphausiid growth stages off southern California, 1953 through 1956. Calif. Coop. Ocean Fish. Invest. Atlas 24: $1-298$.

Campbell, R. W., and J. F. Dower. 2003. Role of lipids in the maintenance of neutral buoyancy by zooplankton. Mar. Ecol. Prog. Ser. 263: 93-99.

Cowey, C. B., J. G. Bell, D. Knox, A. Fraser, and A. YounGSON. 1985. Lipid and antioxidant systems in developing eggs of salmon (Salmo salar). Lipids 20: 567-572.

Ederington, M. C., G. B. McManus, and H. R. Harvey. 1995. Trophic transfer of fatty-acids, sterols, and triterpenoid alcohols between bacteria, a ciliate, and the copepod Acarcia tonsa. Limnol. Oceanogr. 40: 860-867.

George, R. R., And J. O. Strömberg. 1985. Development of eggs of Antarctic krill Euphausia superba in relation to pressure. Polar Biol. 4: 125-133.

Gómez-Gutiérrez, J. 2002. Hatching mechanism and delayed hatching of the eggs of three broadcast spawning euphausiid species under laboratory conditions. J. Plankton Res. 24: 265-1276.

. 2003. Comparative study of the population dynamics, secondary productivity, and reproductive ecology of the euphausiids Euphausia pacifica and Thysanoessa spinifera in the Oregon upwelling region. Ph.D. dissertation. Oregon State Univ.

, W. T. Peterson, and C. B. Miller. 2005. Cross-shelf life-stage segregation and community structure of the euphausiids off central Oregon (1970-1972). Special issue, U.S. GLOBEC biological and physical studies of plankton, fish and higher trophic level production, distribution, and variability in the Northeast Pacific. Deep-Sea Res. Part II 52: 289-315.

Hadley, N. F. 1985. The adaptive role of lipids in biological systems. Wiley.

Hagen, W., E. S. Van Vleet, and G. Kattner. 1996. Seasonal lipid storage as overwintering strategy of Antarctic krill. Mar. Ecol. Prog. Ser. 134: 85-89.

Harrington, S. A., and P. G. Thomas. 1987. Observations on spawning by Euphausia crystallorophias from waters adjacent to Enderby Land (east Antarctica) and speculations on the early ontogenetic ecology of neritic euphausiids. Polar Biol. 7: 93-95.

Harrison, K. E. 1990. The role of nutrition in maturation, reproduction and embryonic development of decapod crustacean: A review. J. Shellfish Res. 9: 1-28.

Harvey, H. R., G. Eglinton, S. C. M. O’Hara, and E. D. S. Corner. 1987. Biotransformation and assimilation of dietary lipids by Calanus feeding on a dinoflagellate. Geochim. Cosmochim. Acta. 51: 3031-3040.

Hofmann, E. E., And Y. S. HüsrevoĞlu. 2003. A circumpolar modeling study of habitat control of Antarctic krill (Euphausia superba) reproductive success. Deep-Sea Res. Part II 50: $3121-3142$.
Huyer, A., J. H. Fleischbein, J. Keister, P. M. Kosro, N. Perlin, R. L. Smith, and P. A. Wheeler. 2005. Two coastal upwelling domains in the northern California current system. J. Mar. Res. 63: 901-929.

Iguchi, N., AND T. IkedA. 1994. Experimental study on brood size, egg hatchability and early development time of the euphausiid Euphausia pacifica from Toyama Bay, Southern Japan Sea. Bull. Japan Sea. Nat. Fish. Res. Inst. 44: 4957.

Irigoien, X. 2004. Some ideas about the role of lipids in the life cycle of Calanus finmarchicus. J. Plankton Res. 26: 259-263.

Ju, S.-J., AND H. R. Harvey. 2004. Lipids as markers of nutritional condition and diet in the Antarctic krill Euphausia superba and Euphausia crystallorophias during austral winter. Deep-Sea Res. Part II 51: 2199-2214.

Kattner, G., AND W. Hagen. 1998. Lipid metabolism of the Antarctic euphausiid Euphausia crystallorophias and its ecological implications. Mar. Ecol. Prog. Ser. 170: 203-213.

Knutsen, T., M. WebJørn, And L. Calise. 2001. Determining the mass density of marine copepods and their eggs with a critical focus on some of the previously used methods. J. Plankton Res. 23: 859-873.

Marschall, H. P. 1983. Sinking speed, density and size of euphausiids eggs. Meeresforsch 30: 1-9.

- AND H. J. Hirche. 1984. Development of eggs and nauplii of Euphausia superba. Polar Biol. 2: 245-250.

Mayzaud, P., M. Boutoute, and F. Alonzo. 2003. Lipid composition of the euphausiids Euphausia vallentini and Thysanoessa macrura during summer in the southern Indian Ocean. Antarctic Sci. 15: 463-475.

McAllen, R. J., A. C. Taylor, and J. Davenport. 1998. Osmotic and body density response in the harpacticoid Tigriopus brevicornis in supralittoral rock pools. J. Mar. Biol. Assoc. U. K. 78: $1143-1153$.

Nelken, L. H. 1990. Densities of vapors, liquids and solids, p. 191-19-14. In W. J. Lyman, W. F. Reehl, and D. H. Rosenblatt [eds.], Handbook of chemical property estimation methodsenvironmental behavior of organic compounds. American Chemical Society.

Nichols, P. D., J. B. Guckert, and D. C. White. 1986. Determination of monounsaturated fatty acid double-bond position and geometry for microbial monocultures and complex consortia by capillary GC-MS of their dimethyl disulphide adducts. J. Microbiol. Methods 5: 49-55.

Quetin, L. B., AND R. M. Ross. 1984. Depth distribution of developing Euphausia superba embryos, predicted from sinking rates. Mar. Biol. 79: 47-53.

, AND - 1989. Effects of oxygen, temperature, and age on the metabolic rate of the embryos and early larval stages of the Antarctic krill Euphausia superba Dana. J. Exp. Mar. Biol. Ecol. 125: 43-62.

Ross, R. M. 1981. Laboratory culture and development of Euphausia pacifica. Limnol. Oceanogr. 26: 235-246.

- AND L. B. Quetin. 1985. The effect of pressure on the sinking rates of the embryos of the Antarctic krill, Euphausia superba. Deep-Sea Res. 32: 799-807.

SARgent, J. R. 1995. Origins and functions of egg lipids: Nutritional implications, p. 353-373. In N. R. Bromage and R. J. Roberts [eds.], Broodstock management and egg and larval quality. Blackwell.

Suchmann, C., L. E. A. Daly, J. E. Keister, W. T. Peterson, and R. D. Brodeur. In press. Prey selection and predation potential of scyphomedusae in a highly productive upwelling region. Mar. Ecol. Prog. Ser. 
Timofeev, S. F. 1990. Vertical distribution of eggs and early larvae of euphausiids in the Barent Sea, p. 102-107. In V. L. Kasyanov [ed.], Biology of marine plankton. Far Eastern Branch, USSR Academy of Science.

Virtue, P., S. Nicol, And P. D. Nichols. 1993. Changes in the digestive gland of Euphausia superba during short-term starvation: lipid class, fatty acid and sterol content and composition. Mar. Biol. 117: 441-448.

Visser, A. W., And S. H. JónAsdótTir. 1999. Lipids, buoyancy and the seasonal vertical migration of Calanus finmarchicus. Fish. Oceanogr. 8: 100-106.
Watanabe, T. 1993. Importance of docosahexaenoic acid in marine larval fish. J. World Aquacult. Soc. 24: 152-161.

Williams, R., AND J. A. Lindley. 1982. Variability in the abundance, vertical distribution and ontogenetic migrations of Thysanoessa longicaudata (Crustacea: Euphausiacea) in the North-Eastern Atlantic Ocean. Mar. Biol. 69: 321-330.

Received: 5 September 2005

Accepted: 3 April 2006

Amended: 18 April 2006 